\title{
Reference Values of Gait Speed and Gait Spatiotemporal Parameters for a South East Asian Population: The Yishun Study
}

This article was published in the following Dove Press journal:

Clinical Interventions in Aging

\author{
Lay Khoon Lau $\mathbb{D}^{\prime}$ \\ Shiou Liang Wee (iD) ${ }^{1,2}$ \\ Wei Jun Benedict Pang (iD) \\ Kexun Kenneth Chen (iD) \\ Khalid Abdul Jabbar' \\ Philip Lin Kiat Yap ${ }^{1,3}$ \\ Jagadish Ullal Mallya ${ }^{1,3}$ \\ Daniella Hui Min $\mathrm{Ng}^{\prime}$ \\ Queenie Lin Ling Tan \\ Wei Ting Seah (D) \\ Tze Pin Ng (D) 1,4 \\ 'Geriatric Education and Research \\ Institute (GERI), Singapore; ${ }^{2}$ Faculty of \\ Health and Social Sciences, Singapore \\ Institute of Technology, Singapore; \\ ${ }^{3}$ Geriatric Medicine, Khoo Teck Puat \\ Hospital, Singapore; ${ }^{4}$ Department of \\ Psychological Medicine, National \\ University of Singapore, Singapore
}

Correspondence: Shiou Liang Wee; Lay Khoon Lau

Tel +6565924606; +65 6807803 I

Email weeshiouliang@gmail.com;

lau.charlene.lk@geri.com.sg
Background: Age-related slowing of gait has been reported to start as early as the fifth decade and accelerate beyond the seventh decade of life. A single cut-off for slow gait may not be appropriate for men and women of different ages. We aimed to report reference values for gait speed and spatiotemporal gait parameters of adult age groups in a South East Asian population. Methods: A total of 507 community-dwelling adults, aged 21-90 years were recruited into the study through random sampling, filling quotas of 20-40 participants in each sex and age group (10-year age groups between 21 and 60 years; 5-year age groups beyond age 60 years). Demographic data, height, weight and information on comorbidities were recorded. Habitual gait speed and spatiotemporal parameters were measured, and the average of three trials was recorded using the GAITRite system.

Results: Gait speed peaked in their 40s for both men and women, but the trajectories differed slightly across age groups. Although similar for men in their 50s and $60 \mathrm{~s}$, gait speed was significantly slower among those aged 71 years and older. For women beyond 50 years old, gait slowed with age. After adjusting for height, women were found to walk significantly faster and with a longer step length than men. Women also walked with a significantly narrower stride width and less external rotation of the feet. The lowest quintile for gait speed in our study cohort was $0.9 \mathrm{~m} / \mathrm{s}$, below the recommended cut-off of $1.0 \mathrm{~m} / \mathrm{s}$.

Conclusion: We established the reference values as well as the quintiles for gait speed and spatiotemporal gait parameters across adult age groups in a multi-ethnic Asian population. This contributes to a valuable database for gait assessment and evaluation of preventive or rehabilitative programs.

Keywords: habitual gait speed and spatiotemporal parameters, normative data, quintile, comorbidities, community-dwelling adults

\section{Introduction}

Aging is associated with a decline in gait speed. Slow gait is a determinant for sarcopenia ${ }^{1}$ and cognitive frailty. ${ }^{2}$ Disease-associated abnormal gait, such as foot pain $^{3}$ and Parkinson disease, ${ }^{4}$ predispose older adults to a greater fall risk. Hence, gait impairment predicts institutionalization and early mortality. ${ }^{5}$ Gait assessment is not only applicable to rehabilitation settings, but also relevant to population health screening for early identification of gait abnormality so as to institute interventions to delay functional impairment. Population-specific reference values would be valuable to healthcare professionals for assessment of gait and evaluation of preventive and rehabilitative programs. 
The Asian Working Group for Sarcopenia (AWGS) (2019) recommended a habitual gait speed cut-off of less than $1.0 \mathrm{~m} / \mathrm{s}$ as one of the diagnostic criteria for sarcopenia and low physical performance. ${ }^{1}$ However, the application of a single cut-off value for older adults of different age groups may result in an overdiagnosis or underdiagnosis of impairment. The slowing of gait has been reported to start after the sixth decade and accelerate beyond the seventh decade of life in healthy adults. ${ }^{6,7}$ Reference values provided for each decade of life could better differentiate normal aging gait from pathological gait and better inform gait assessment.

Although there are some South East Asian studies on habitual gait, ${ }^{6,8-10}$ most of these studies focused only on the elderly aged 60 years old and above., ${ }^{9,10}$ In studying the younger population (40 years old and above), Yoshimura et al $(2011)^{8}$ reported that gait speed peaked between 40 and 49 years of age, before declining thereafter. However, it is still unclear how gait speed changes prior to the fifth decade of life. There is evidence that the grey matter volume of the prefrontal cortex, which is associated with gait speed, ${ }^{11}$ decreases with age starting from the third decade. ${ }^{12}$ Therefore, studying the gait parameters of younger adults can be relevant in exemplifying our understanding of agerelated changes in gait across the adult life.

Gait speed is the product of cadence and step length. ${ }^{13}$ Other than speed, there are important differences and changes in the spatiotemporal parameters of habitual gait between sex and across age, respectively. For example, women have higher cadence ${ }^{13}$ but shorter step length ${ }^{14}$ than men. In addition to the step length decline observed in patients with Parkinson disease, ${ }^{15}$ Taniguchi et al $(2012)^{16}$ also proposed that step length is a better predictor of cognitive decline than gait speed. Hence, it is important to consider the changes in spatiotemporal gait parameters to determine the need for earlier intervention. ${ }^{17}$ Similarly, majority of the studies on spatiotemporal gait parameters focused on older adults 70 years old and above. ${ }^{10,14,18}$

The objectives of this study were to determine reference values and examine the trajectories of gait speed and gait spatiotemporal parameters across adult age groups.

\section{Materials and Methods}

\section{Study Setting and Population}

Community-dwelling adults ( $\geq 21$ years) were recruited from the town of Yishun, one of the largest north-residential towns in Singapore, residential population of 220,320 (50.6\% females), with $12.2 \%$ older adults ( $\geq 65$ years), similar to the overall Singapore residential population of 4,026,210 (51.1\% females), with $14.4 \%$ older adults ( $\geq 65$ years). ${ }^{19}$

Random sampling was employed to obtain a representative sample of approximately 300 male and 300 female participants, filling quotas of $20-40$ participants in each sex and nine age groups (10-year age groups between 21 and 60 years; 5-year age groups beyond 60 years). Conventionally, a sample size of 30 or more is considered sufficient for a normative measurement. ${ }^{20}$ A two-stage quota random sampling method was initially adopted (October 2017-February 2019), where a sampling fraction of $20 \%$ of the residents from the $50 \%$ randomly selected public housing blocks was carried out. Subsequently, a one-stage quota random sampling method was adopted (March-November 2019) where residents of the randomly selected housing blocks (50\% of the housing blocks of Yishun) were contacted via door-to-door recruitment method. Non-ambulant individuals, those with neuromuscular diseases, cognitive impairment, dementia, acute musculoskeletal injuries, acquiring more than five poorly controlled comorbidities, pregnancy and any physical disability or condition that limit their activities of daily living were excluded from this study. Older adults (76 years old and above) who met study inclusion criteria were also additionally recruited from community and senior activity centers. The overall response rate was $39 \%$. Informed consent was obtained from participants prior to their enrolment into this study. Ethics approval was obtained from National Healthcare Group Domain Specific Review Board (Reference No. 2017/00212) as our institution does not have its own ethics board and all its human research studies have to be reviewed and approved by National Healthcare Group Domain Specific Review Board. This cross-sectional study was conducted in accordance with the Declaration of Helsinki and Strengthening the Reporting of Observational Studies in Epidemiology (STROBE) guidelines.

\section{Gait Measurements}

A $6 \mathrm{~m}$ electronic walkway system, GAITRite ${ }^{\circledR}$ (CIR systems, USA), embedded with pressure-activated sensors, was used to measure the spatiotemporal aspects of gait. ${ }^{21-23}$ Using the GAITRite system, Brach et al $(2008)^{24}$ have previously established excellent test-retest reliability for gait speed and gait parameters. It has been reported to provide reliable and accurate measurements of spatiotemporal gait parameters. ${ }^{23}$ Prior to the gait measurement, the demographical data, such as age, sex, race 
and medical history of participants were recorded. Height and weight were measured. The participants completed three trials at a habitual walking pace, barefooted, initiating and terminating their walk $1 \mathrm{~m}$ before and after the recording field of the sensor mats. ${ }^{14,22,23}$ This was to minimize the acceleration and deceleration effects. The data were sampled at $120 \mathrm{~Hz}$. The spatiotemporal parameters were recorded and the average of three trials was calculated for analysis. A valid walking trial should consist of a minimum of six footprints (three strides). ${ }^{25}$ Readings between the right and left extremities were averaged. ${ }^{10}$

\section{Data Analysis}

Gait speed was calculated by dividing the total step length with total step time. ${ }^{26}$ Step length was the anteriorposterior distance from the heel of one footprint to the heel of the opposite footprint ${ }^{14}$ while step width referred to lateral (diagonal) distance from the midpoint of one footprint to the midpoint of the previous footprint. ${ }^{27}$ Stride width referred to the lateral distance from the heel of one footprint to the line of progression formed by two consecutive footprints (heels) of the opposite foot. ${ }^{23}$ The angle between midline of the footprint with the line of progression formed by two consecutive footprints of the opposite foot (toe-in/toe-out) was calculated to compute the amount of foot external rotation. A positive value indicates toe-out (feet external rotation). ${ }^{27}$ The time elapsed between the last contact of the current footfall to the first contact of the next footfall (same foot) was single support time. ${ }^{14}$ Double support time was the time elapsed between the initial heel contact of one footfall to toe-off of the opposite footfall. Percentage of stance time (Stance time $[\% \mathrm{GC}]$ ) was calculated by normalizing stance time with stride time. ${ }^{14}$ As some of the gait parameters are influenced by the height of an individual, normalization of the respective gait parameters with height was performed. Habitual gait speed (gait speed/height), ${ }^{9}$ step length (step length/height), ${ }^{28}$ and step width (step width/height) were normalized with height, while cadence was normalized by the square root of height (cadence $\mathrm{x}$ /height). ${ }^{29}$

Statistical analyses were performed with SPSS (26.0, USA). Normality of the variables was examined using histogram. Depending on the distribution pattern, the sex differences for each continuous variable were calculated using the independent $t$-test or Mann-Whitney $U$-test. Chisquared test was used to examine the sex differences for categorical data. Univariate General Linear Model (GLM) was used to examine the age group differences (across nine groups) for each gait parameter and sex as it has demonstrated robustness in handling any deviation from normality. Two-way ANOVA was used to examine the interaction between sex and cardiovascular diseases (diabetes, hypertension and hypercholesterolemia) for gait speed and gait parameters, controlling for years of education. Statistical significance was set at a $p$ value of equal to or less than 0.05. Additionally, we calculated the quintiles for gait speed and gait parameters, by sex and age groups.

\section{Results}

A total of 542 participants were recruited into the study. Majority (94.1\%) were recruited from the randomly selected blocks. Thirty-five participants (two did not complete testing, one withdrew, one had Schizophrenia, 16 post total knee or hip arthroplasty and 15 had arthritis) were excluded from analyses. Hence, data from 507 participants were analyzed.

Table 1 shows the descriptive statistics for age, education, ethnicity and chronic diseases of participants. There were no significant differences between men and women except for heart disease $(p<0.01)$ and osteoporosis $(p=0.02)$. Comparisons in gait parameters between men and women are shown in Table 2. Women and men had similar gait speed prior to the adjustment for height $(p=0.83)$. Men had significantly greater step length $(+2.21 \mathrm{~cm}, p<0.01)$ and step width $(+2.77 \mathrm{~cm}, p<0.01)$ but lower cadence $(-5$ steps $/ \mathrm{min}, p<0.01)$. However, with height adjustment, women were found to walk faster than men with a mean difference of $0.05 \mathrm{~s}^{-1}(p<0.01)$ (Table 2). They also had a significantly greater height-adjusted step length $(+0.01, p=0.01)$ but similar height-adjusted cadence $(p=0.58)$ as men. Although men had longer single-leg stance time $(+0.01 \mathrm{~s}, p<0.01)$ and double support time $(+0.02 \mathrm{~s}, p<0.01)$ as compared to women, there was no significant difference in the stance time (\%GC) $(p=0.07)$. Women walked with a significantly narrower stride width $(-1.37 \mathrm{~cm}, p<0.01)$. Moreover, they externally rotated their feet $\left(-3.91^{\circ}, p<0.01\right)$ lesser than men during walking.

Two-way ANOVA results showed that the interaction effects between sex and chronic diseases (diabetes, hypertension and hypercholesterolemia) were significant for adjusted step length $(p=0.04)$, and double support time $(p=0.03$ ) (Table 5). Adjusting for education, men with hypertension and hypercholesterolemia, with or without diabetes walked slower $(p>0.05)$ with significantly shorter step length $(p<0.05)$ as compared to women who had the same diseases. Moreover, in comparison, men with 
Table I Demographical Data of Participants

\begin{tabular}{|c|c|c|c|}
\hline \multirow[t]{2}{*}{ Variables } & \multicolumn{2}{|c|}{ Mean (SD) or $n(\%)$} & \multirow[t]{2}{*}{$p$ value } \\
\hline & $\begin{array}{l}\text { Men } \\
(n=22 I)\end{array}$ & $\begin{array}{l}\text { Women } \\
(n=286)\end{array}$ & \\
\hline Age $(\text { years })^{\mathrm{a}}$ & $64.00^{\mathrm{b}}$ & $60.50^{\mathrm{b}}$ & 0.33 \\
\hline Height (cm) & $166.81(6.97)$ & $\mid 55.26(6.4 \mid)$ & $<0.01$ \\
\hline \multicolumn{4}{|l|}{ Age group, $n(\%)$} \\
\hline $21-30$ & $28(12.70)$ & $32(11.20)$ & 0.58 \\
\hline $31-40$ & $26(11.80)$ & $34(11.90)$ & \\
\hline $4 I-50$ & $20(9.00)$ & $40(14.00)$ & \\
\hline $5 I-60$ & $20(9.00)$ & $37(12.90)$ & \\
\hline $6 I-65$ & $29(13.10)$ & $29(10.10)$ & \\
\hline $66-70$ & $23(10.40)$ & $29(10.10)$ & \\
\hline $7 \mid-75$ & $29(13.10)$ & $29(10.10)$ & \\
\hline $76-80$ & $24(10.90)$ & $28(9.80)$ & \\
\hline$\geq 81$ & $22(10.00)$ & $28(9.80)$ & \\
\hline Education (years) ${ }^{\mathrm{a}}$ & $10^{\mathrm{b}}$ & $9^{\mathrm{b}}$ & 0.10 \\
\hline \multicolumn{4}{|l|}{ Ethnicity, n(\%) } \\
\hline Chinese & $180(8 \mid .40)$ & $230(80.40)$ & 0.94 \\
\hline Malay & $18(8.10)$ & $27(9.40)$ & \\
\hline Indian & $17(7.70)$ & $20(7.00)$ & \\
\hline Others & $6(2.70)$ & $9(3.10)$ & \\
\hline \multicolumn{4}{|l|}{ Chronic disease, $n(\%)$} \\
\hline Diabetes & $38(17.20)$ & $37(12.90)$ & 0.21 \\
\hline Hypertension & $80(36.20)$ & $96(33.60)$ & 0.57 \\
\hline Hypercholesterolemia & $83(37.60)$ & $102(35.70)$ & 0.71 \\
\hline Heart disease & $27(12.20)$ & $9(3.10)$ & $<0.01$ \\
\hline Asthma & $10(4.50)$ & $10(3.50)$ & 0.65 \\
\hline Kidney disease & $5(2.30)$ & $5(1.70)$ & 0.75 \\
\hline Depression & $\mathrm{I}(0.50)$ & $6(2.10)$ & 0.14 \\
\hline Osteoporosis & $3(1.40)$ & $14(4.90)$ & 0.04 \\
\hline Visual problem & $17(7.70)$ & $14(4.90)$ & 0.20 \\
\hline Hearing problem & $10(4.50)$ & $10(3.50)$ & 0.65 \\
\hline
\end{tabular}

Notes: ${ }^{a}$ Mann-Whitney U-test; ${ }^{b}$ median.

hypertension, hypercholesterolemia and diabetes also had significantly longer double support time $(p=0.03)$ in walking. There was no significant interaction effect between sex and any of the three chronic diseases in isolation $(p>0.05)$. On the contrary, the sex differences for stride width, feet external rotation and single support time were independent of the three chronic diseases.

The quintiles of gait parameters for each age group were reported separately for men (Table 6) and women (Table 7). Aging was associated with a decline in gait speed (both with and without adjustment for height) in both genders $(p<0.01)$ (Tables 3 and 4$)$. The most notable age-related difference in gait speed, for men and women occurred in the age groups of above 70 years (Tables 3 and
4). The age effects on spatiotemporal gait parameters were significant $(p<0.05)$ for both genders, except for stride width, cadence and adjusted cadence for men $(p>0.05)$.

\section{Discussion}

In this study, we establish the reference values as well as the quintiles for gait speed and spatiotemporal gait parameters across adult age groups in a multi-ethnic Asian adult population. Gait speed for men and women was fastest for the age group in their $40 \mathrm{~s}$, but the trajectories of gait speed across age groups differed slightly. Gait speed was similar for men in their 50s and 60s, but those aged 71 and above were observed to walk significantly slower. For women beyond 50 years old, we observed a downward trend for gait speed with age, with significantly slower walking speeds for those in the age group of 71 to 75 , and also those beyond 75 years. Adjusting for height, women walked significantly faster with a longer step length than men, possibly confounded by the comorbidities in men. However, women walked with a significantly narrower stride width and less external rotation of the feet than men. The lowest quintile for gait speed in our cohort was $0.9 \mathrm{~m} / \mathrm{s}$, which is lower than the recommended AWGS cut-off of $1.0 \mathrm{~m} / \mathrm{s}^{1}$

We present the reference values as well as the quintiles for gait speed and gait parameters for South East Asian adults. As expected, we observed a decline in gait speed among the older age groups. ${ }^{10}$ Although the relationship between gait speed and age appeared to be elliptical, ${ }^{13}$ the trajectories of gait speed across the adult age spectrum were dissimilar in men and women. In men, heightadjusted gait speed was fastest for those in their 40s, plateauing till the seventh decade, before declining significantly thereafter. Similarly, adjusted gait speed for women peaked in their $40 \mathrm{~s}$, followed by a downward trend that exacerbated for those in the age groups, between 71 and 75 years and 76 and 80 years.

The sex variation in the trajectory of gait speed could partly be attributed to the interaction between step length and cadence. The age-associated trend for reduction in height-adjusted step length ${ }^{14,18}$ was significant in both men and women. Shorter step length has been found to serve as a compensatory mechanism in preserving stability and avoiding falls in older adults. ${ }^{30}$ Height-adjusted step length was significantly shorter for women beyond 65 years old, but height-adjusted cadence did not differ significantly from early adulthood till 75 years old. Beyond that, the compound effect of accentuated declines in both 
Table 2 Comparison of Gait Parameters Between Men and Women

\begin{tabular}{|c|c|c|c|c|}
\hline \multirow[t]{2}{*}{ Variables } & \multicolumn{2}{|l|}{ Mean (SD) } & \multirow[t]{2}{*}{ Mean Difference $(95 \% \mathrm{Cl})$} & \multirow[t]{2}{*}{$p$ value } \\
\hline & Men $(n=22 I)$ & Women $(n=286)$ & & \\
\hline Gait speed (cm/s) & $106.4 \mid(20.04)$ & $106.79(18.86)$ & $-0.37(-3.80,3.07)$ & 0.83 \\
\hline Height-adjusted gait speed $\left(s^{-1}\right)$ & $0.64(0.12)$ & $0.69(0.11)$ & $-0.05(-0.07,-0.03)$ & $<0.01$ \\
\hline Step length $(\mathrm{cm})$ & $57.60(9.31)$ & $55.39(7.14)$ & $2.21(0.73,3.70)$ & $<0.01$ \\
\hline Height-adjusted step length & $0.34(0.05)$ & $0.36(0.04)$ & $-0.01(-0.02,<-0.01)$ & 0.01 \\
\hline Step width $(\mathrm{cm})$ & $59.36(8.64)$ & $56.59(6.80)$ & $2.77(1.42,4.12)$ & $<0.01$ \\
\hline Height-adjusted step width & $0.36(0.05)$ & $0.36(0.04)$ & $-0.01(-0.02,<0.01)$ & 0.02 \\
\hline Stride width $(\mathrm{cm})$ & $10.74(3.11)$ & $9.37(2.68)$ & $1.37(0.86, \mid .87)$ & $<0.01$ \\
\hline Feet external rotation $\left({ }^{\circ}\right)$ & $8.5 \mathrm{I}(6.23)$ & $4.60(5.62)$ & $3.91(2.87,4.95)$ & $<0.01$ \\
\hline Stance time $(\% G C)$ & $62.09(1.87)$ & $61.79(1.84)$ & $0.30(<-0.02,0.63)$ & 0.07 \\
\hline Single support time (s) & $0.4 I(0.04)$ & $0.40(0.03)$ & $0.01(0.01,0.02)$ & $<0.01$ \\
\hline Double support time (s) & $0.27(0.05)$ & $0.25(0.06)$ & $0.02(0.01,0.03)$ & $<0.01$ \\
\hline Cadence (steps/min) & $\mathrm{III}(\mathrm{I0})$ & $115(11)$ & $-5(-6,-3)$ & $<0.01$ \\
\hline Height-adjusted cadence & $1428(\mid 19)$ & $1434(133)$ & $-6(-28,16)$ & 0.58 \\
\hline
\end{tabular}

Abbreviations: Mean (SD), mean (standard deviation); Stance time (\%GC), percentage of stance time out of gait cycle.

step length and cadence could explain for the accelerated slowing of gait speed among women 76 years old and above. Furthermore, we postulate that other factors, such as menopause, could possibly regulate gait speed as well. The abrupt decrease in estrogen production in women generally occurs around 50 years of age, ${ }^{31}$ which has been reported to cause a slowing gait. ${ }^{32}$ This could possibly explain for the gradual gait speed decline of our female participants beyond 50 years old. On the contrary, the relatively consistent cadence ${ }^{21}$ across adulthood in men likely protected them against gait speed decline at least up till the age of 70 . The significantly slower gait speed in men beyond the seventh decade, especially those above 80 years old was accompanied by an exacerbated shortening in step length as well.

Step width refers to the distance (diagonal) between the right and left mid foot ${ }^{27}$; hence, it is associated with step length. Although Kawai et al documented an increase in step width with advancing age,${ }^{10}$ we observed a reversing trend instead. Gluteus Medius, the agonist muscle for hip abduction, stabilizes the pelvic in locomotion. ${ }^{33}$ Though the measurement of its muscular strength is beyond the scope of this study, the age-associated decline of gluteus medius strength in older adults has been reported to start after 45 years old and accelerate after 70 years of age. ${ }^{34}$ Reduced Gluteus Medius strength is associated with a reduced step width. ${ }^{35}$ The widest step width was observed in men and women, in their 40s and 30s, respectively, followed by a downward trend with age. In comparison, our older adults appeared to walk slower as compared to other Asian ${ }^{6,8-10}$ and Caucasian older adults. ${ }^{14,23}$ Whether the compound effect of decreased step length and step width accentuates the slower walking speed in our older adults, and whether this could increase fall risks in our comparably vulnerable population, warrants further investigation.

In 2019, the AWGS revised their cut-off value for habitual gait speed from $\leq 0.8 \mathrm{~m} / \mathrm{s}$ to $<1.0 \mathrm{~m} / \mathrm{s}$. ${ }^{1}$ Walking speed of less than $1.0 \mathrm{~m} / \mathrm{s}$ has been reported to be associated with disability ${ }^{36}$ and sarcopenia ${ }^{37}$ among Asian populations. The lowest quintile for gait speed in our study cohort was $0.9 \mathrm{~m} / \mathrm{s}$ for men and women. This is in agreement with the recommendation by AWGS that sexspecific cut-off values are not needed. However, when considering both young and older adults, the lowest quintile for gait speed was lower as compared to a previous study on Japanese elderly, ${ }^{10}$ and below the recommended cut-off by AWGS as well. Hence, further studies may be required to examine if a revised cut-off for gait speed of less than $0.9 \mathrm{~m} / \mathrm{s}$, and its association with increased risks of physical disability and cognitive impairments, would be more appropriate for the Singapore population.

In addition to shorter step length, older adults, especially those beyond 75 years old, appeared to naturally enhance their stability or balance by increasing their stride width and double support time. ${ }^{14,23}$ Older adults beyond 70 years old, especially women in their ninth decade walked with wider stride width. We observed the narrowest stride width among adults aged 66 to 70 years, followed by the widening of stride width beyond 70 years. 


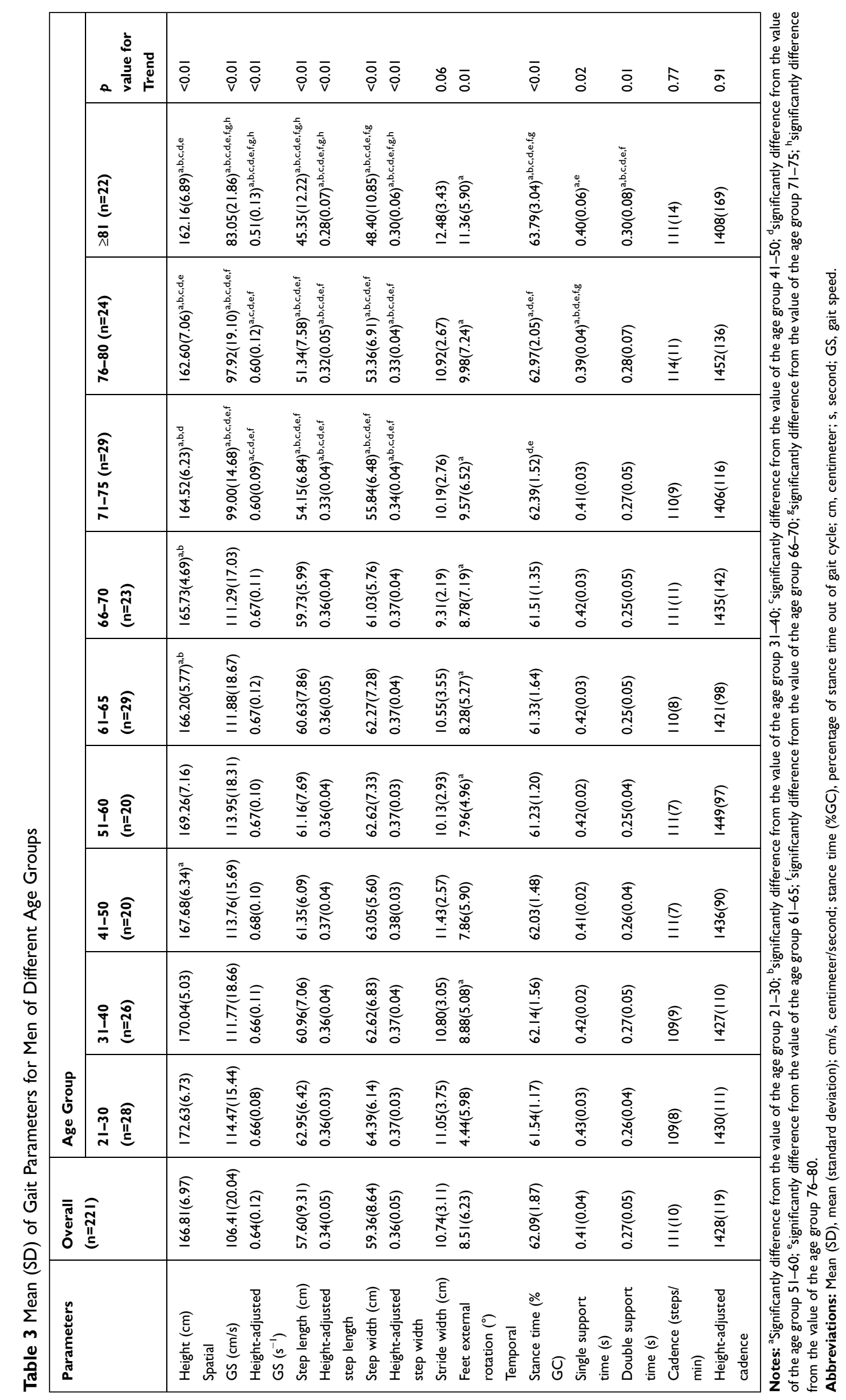




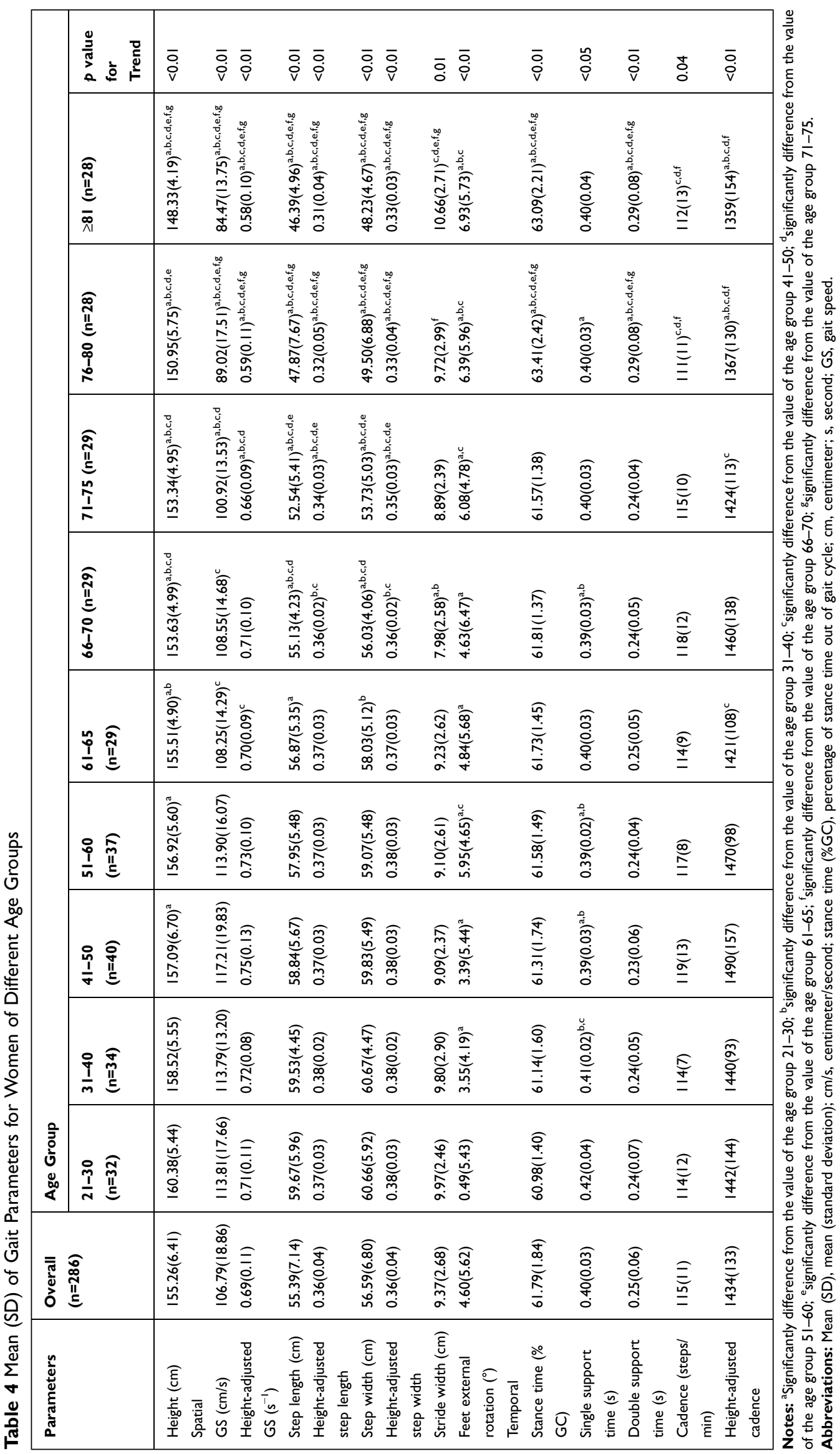




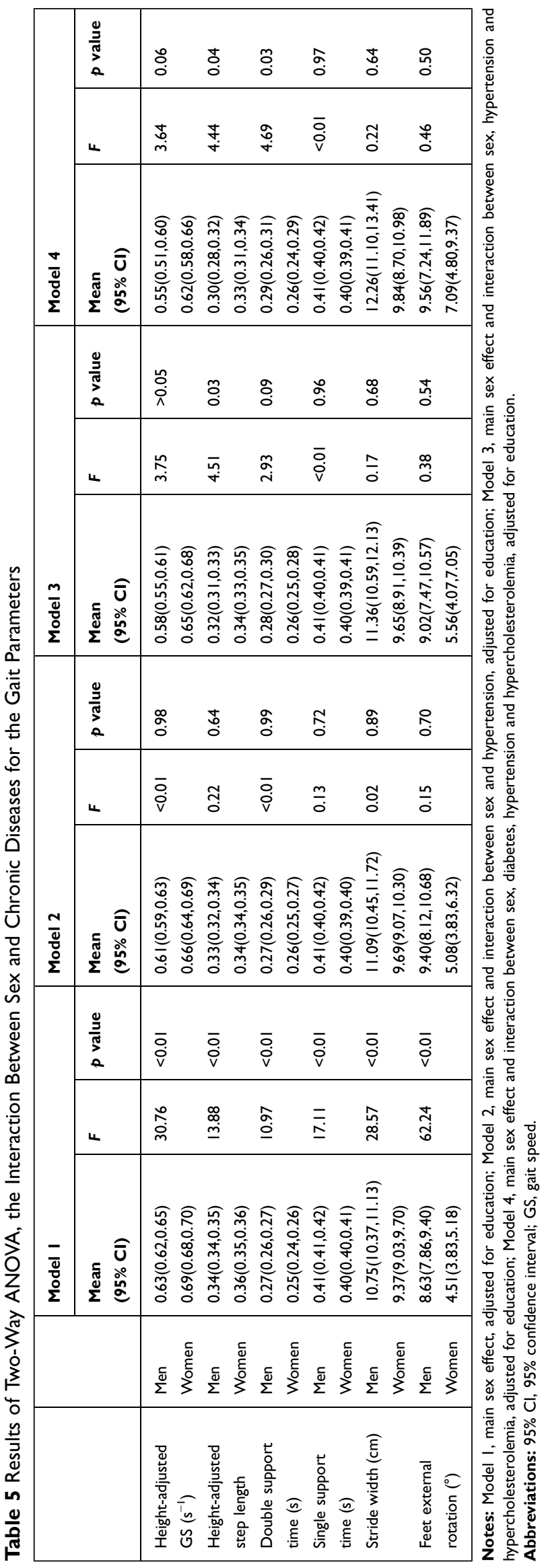

We are not able to draw any causal relationship between stride width and gait speed in this cross-sectional study. However, future studies may examine if an accelerated gait speed decline in those above 70 years old was associated with the narrowest stride width for those aged 66 to 70 years, possibly as a protective mechanism to preserve stability in the fear of falling. Additionally, a novel finding of this study was men and women of older age groups were also found to externally rotate their feet significantly greater than those in younger age groups, possibly to further enhance their balance.

Although there are some reports that men walk faster than women, ${ }^{6,8,14}$ after adjusting for height, the women walked significantly faster than men. This phenomenon was similarly observed for step length. There was high prevalence of hypertension and hypercholesterolemia among our participants ( $\geq 34 \%$ ). Hence, a separate analysis was carried out to examine the interaction between sex and chronic diseases (diabetes, hypertension and hypercholesterolemia), adjusting for education. Men with hypertension, hypercholesterolemia and diabetes (accounting for $10.9 \%$ of male participants) walked slower with shorter step length and increased double support time as compared to women who had the same diseases (9.4\% of female participants). Although the cause and effect of chronic diseases is beyond the scope of this study, hypertension, ${ }^{38,39}$ hypercholesterolemia ${ }^{39}$ and diabetes $^{38}$ have been reported to cause arterial stiffness, ${ }^{38}$ which is associated with slower gait speed. ${ }^{40}$

Moreover, men with both hypertension and hypercholesterolemia (accounting for $24.9 \%$ of male participants), had shorter step length in walking as compared to women who had the same diseases (22.7\% of female participants). The sex differences (for those with hypertension and hypercholesterolemia) in walking speed was lesser, closed to a significant level. These findings suggest that the negative effect of chronic diseases on step length could possibly precipitate the slowing of gait speed in this population group. This further emphasizes the importance of taking into consideration the assessment of spatiotemporal parameters, in addition to gait speed to early detect alteration of gait, better facilitate the implementation of preventive programs. The reason for the compound negative effect of these three chronic diseases on the decline in gait speed among men warrants further investigation.

In agreement with previous findings, ${ }^{13,14}$ women walked with higher cadence as compared to men. However, the difference was attenuated when cadence was normalized with height. In comparison, men spent 
Table 6 Quintile of Gait Parameters for Men of Different Age Groups

\begin{tabular}{|c|c|c|c|c|c|c|c|c|c|c|c|}
\hline \multirow[t]{2}{*}{ Gait Parameters } & \multirow[t]{2}{*}{ Percentile } & \multirow{2}{*}{$\begin{array}{l}\text { Overall } \\
(n=221)\end{array}$} & \multicolumn{9}{|c|}{ Age Group } \\
\hline & & & $\begin{array}{l}21-30 \\
(n=28)\end{array}$ & $\begin{array}{l}31-40 \\
(n=26)\end{array}$ & $\begin{array}{l}41-50 \\
(n=20)\end{array}$ & $\begin{array}{l}5 I-60 \\
(n=20)\end{array}$ & $\begin{array}{l}6 I-65 \\
(n=29)\end{array}$ & $\begin{array}{l}66-70 \\
(n=23)\end{array}$ & $\begin{array}{l}7 I-75 \\
(n=29)\end{array}$ & $\begin{array}{l}76-80 \\
(n=24)\end{array}$ & $\begin{array}{l}\geq 81 \\
(n=22)\end{array}$ \\
\hline \multirow[t]{4}{*}{$\mathrm{GS}(\mathrm{cm} / \mathrm{s})$} & 80 & 123.83 & 125.30 & 126.83 & 129.78 & 130.36 & 132.22 & 126.35 & 108.74 & 112.57 & 100.81 \\
\hline & 60 & 1111.30 & 117.90 & 120.69 & 113.73 & 118.02 & 116.93 & 116.81 & 103.14 & 103.93 & 93.01 \\
\hline & 40 & 103.10 & 110.09 & 108.09 & 107.73 & 109.22 & 108.10 & 109.08 & 96.50 & 95.92 & 73.20 \\
\hline & 20 & 89.88 & 103.33 & 89.13 & 99.36 & 94.52 & 95.86 & 97.10 & 86.43 & 78.65 & 62.94 \\
\hline \multirow{4}{*}{$\begin{array}{l}\text { Height-adjusted GS } \\
\left(\mathrm{s}^{-1}\right)\end{array}$} & 80 & 0.74 & 0.71 & 0.76 & 0.77 & 0.78 & 0.78 & 0.78 & 0.66 & 0.68 & 0.61 \\
\hline & 60 & 0.67 & 0.68 & 0.69 & 0.70 & $0.7 \mathrm{I}$ & 0.70 & 0.70 & 0.63 & 0.65 & 0.57 \\
\hline & 40 & 0.61 & 0.65 & 0.64 & 0.65 & 0.62 & 0.66 & 0.66 & 0.59 & 0.60 & 0.46 \\
\hline & 20 & 0.55 & 0.61 & 0.52 & 0.58 & 0.58 & 0.60 & 0.57 & 0.54 & 0.50 & 0.39 \\
\hline \multirow[t]{4}{*}{ Step length $(\mathrm{cm})$} & 80 & 64.67 & 68.99 & 66.46 & 66.64 & 68.31 & 66.34 & 64.43 & 62.82 & 57.69 & 59.84 \\
\hline & 60 & 61.24 & 63.86 & 62.81 & 62.93 & 62.75 & 63.26 & 63.08 & 54.64 & 51.54 & 51.56 \\
\hline & 40 & 56.39 & 60.69 & 58.54 & 59.99 & 58.30 & 59.69 & 59.56 & 52.49 & 49.46 & 41.30 \\
\hline & 20 & 51.07 & 57.71 & 54.23 & 55.09 & 54.10 & 55.05 & 54.75 & 47.51 & 44.81 & 31.86 \\
\hline \multirow{4}{*}{$\begin{array}{l}\text { Height-adjusted step } \\
\text { length }\end{array}$} & 80 & 0.39 & 0.38 & 0.40 & 0.41 & 0.40 & $0.4 \mathrm{I}$ & 0.40 & 0.37 & 0.36 & 0.35 \\
\hline & 60 & 0.36 & 0.36 & 0.38 & 0.37 & 0.37 & 0.38 & 0.38 & 0.34 & 0.32 & 0.32 \\
\hline & 40 & 0.34 & 0.36 & 0.35 & 0.35 & 0.35 & 0.36 & 0.36 & 0.32 & 0.31 & 0.24 \\
\hline & 20 & 0.31 & 0.35 & 0.32 & 0.33 & 0.32 & 0.33 & 0.32 & 0.30 & 0.28 & 0.20 \\
\hline \multirow[t]{4}{*}{ Step width $(\mathrm{cm})$} & 80 & 66.17 & 69.71 & 67.72 & 67.73 & 69.34 & 68.25 & 65.57 & 64.37 & 58.73 & 61.99 \\
\hline & 60 & 62.74 & 65.56 & 64.09 & 64.27 & 63.88 & 64.18 & 64.11 & 56.11 & 54.54 & 52.81 \\
\hline & 40 & 58.03 & 62.75 & 60.70 & 61.82 & 60.43 & 60.73 & 60.82 & 54.55 & 51.06 & 44.08 \\
\hline & 20 & 53.28 & 59.23 & 55.85 & 56.60 & 56.21 & 56.41 & $56.4 I$ & 48.91 & 46.76 & 37.22 \\
\hline \multirow{4}{*}{$\begin{array}{l}\text { Height-adjusted step } \\
\text { width }\end{array}$} & 80 & 0.39 & 0.39 & 0.40 & 0.42 & 0.41 & 0.42 & 0.41 & 0.38 & 0.37 & 0.36 \\
\hline & 60 & 0.37 & 0.38 & 0.38 & 0.38 & 0.38 & 0.39 & 0.39 & 0.34 & 0.34 & 0.33 \\
\hline & 40 & 0.35 & 0.37 & 0.36 & 0.36 & 0.36 & 0.37 & 0.36 & 0.33 & 0.32 & 0.26 \\
\hline & 20 & 0.32 & 0.35 & 0.33 & 0.35 & 0.34 & 0.35 & 0.33 & 0.32 & 0.29 & 0.24 \\
\hline \multirow[t]{4}{*}{ Stride width $(\mathrm{cm})$} & 80 & 13.27 & 15.19 & 13.47 & 13.45 & 11.67 & 13.05 & 11.04 & 13.04 & 13.24 & 15.09 \\
\hline & 60 & 11.27 & 11.37 & 11.34 & 11.91 & 10.24 & 11.46 & 9.86 & 10.90 & 11.90 & 13.83 \\
\hline & 40 & 9.84 & 10.07 & 10.09 & 9.98 & 9.28 & 9.87 & 8.90 & 8.93 & 10.31 & 12.23 \\
\hline & 20 & 8.29 & 7.90 & 8.16 & 8.93 & 8.31 & 6.75 & 7.26 & 8.04 & 8.16 & 10.99 \\
\hline \multirow{4}{*}{$\begin{array}{l}\text { Feet external rotation } \\
\left({ }^{\circ}\right)\end{array}$} & 80 & 13.49 & 9.08 & 13.55 & 13.89 & 13.00 & 13.16 & 15.50 & 15.99 & 16.56 & 15.44 \\
\hline & 60 & 10.59 & 6.04 & 11.30 & 10.39 & 9.11 & 9.31 & 10.65 & 10.98 & $\mid 1.31$ & 13.37 \\
\hline & 40 & 6.86 & 2.63 & 9.17 & 6.00 & 6.47 & 5.53 & 8.27 & 8.99 & 9.63 & 8.67 \\
\hline & 20 & 3.37 & -1.17 & 3.13 & 2.34 & 3.39 & 3.72 & 2.69 & 4.77 & 3.80 & 6.41 \\
\hline \multirow[t]{4}{*}{ Stance time $(\% \mathrm{GC})$} & 80 & 63.39 & 62.62 & 63.77 & 63.45 & 62.31 & 62.72 & 62.53 & 63.70 & 65.09 & 66.36 \\
\hline & 60 & 62.27 & 61.84 & 62.19 & 62.64 & 61.56 & 61.29 & 61.80 & 62.88 & 63.45 & 65.03 \\
\hline & 40 & 61.48 & 61.08 & 61.53 & 61.54 & 60.75 & 60.65 & 61.38 & 61.61 & 62.29 & 62.30 \\
\hline & 20 & 60.56 & 60.36 & 60.81 & 61.16 & 60.25 & 60.20 & 60.47 & 60.97 & 61.37 & 60.85 \\
\hline \multirow[t]{4}{*}{ Single support time (s) } & 80 & 0.44 & 0.45 & 0.44 & 0.42 & 0.44 & 0.44 & 0.45 & 0.45 & 0.42 & 0.46 \\
\hline & 60 & 0.42 & 0.44 & 0.42 & 0.42 & 0.42 & 0.42 & 0.42 & 0.42 & 0.38 & $0.4 \mathrm{I}$ \\
\hline & 40 & 0.40 & 0.42 & $0.4 I$ & $0.4 I$ & $0.4 I$ & 0.42 & $0.4 I$ & 0.40 & 0.38 & 0.38 \\
\hline & 20 & 0.38 & 0.40 & 0.40 & 0.39 & 0.40 & 0.40 & 0.38 & 0.38 & 0.36 & 0.33 \\
\hline \multirow[t]{3}{*}{ Double support time (s) } & 80 & 0.30 & 0.28 & 0.33 & 0.30 & 0.28 & 0.28 & 0.30 & 0.30 & 0.32 & 0.37 \\
\hline & 60 & 0.27 & 0.25 & 0.27 & 0.28 & 0.25 & 0.25 & 0.27 & 0.29 & 0.28 & 0.31 \\
\hline & 40 & 0.25 & 0.24 & 0.25 & 0.25 & 0.23 & 0.23 & 0.23 & 0.27 & 0.26 & 0.27 \\
\hline
\end{tabular}


Table 6 (Continued).

\begin{tabular}{|c|c|c|c|c|c|c|c|c|c|c|c|}
\hline \multirow[t]{2}{*}{ Gait Parameters } & \multirow[t]{2}{*}{ Percentile } & \multirow{2}{*}{$\begin{array}{l}\text { Overall } \\
(n=221)\end{array}$} & \multicolumn{9}{|c|}{ Age Group } \\
\hline & & & $\begin{array}{l}21-30 \\
(n=28)\end{array}$ & $\begin{array}{l}3 I-40 \\
(n=26)\end{array}$ & $\begin{array}{l}4 I-50 \\
(n=20)\end{array}$ & $\begin{array}{l}5 I-60 \\
(n=20)\end{array}$ & $\begin{array}{l}6 I-65 \\
(n=29)\end{array}$ & $\begin{array}{l}66-70 \\
(n=23)\end{array}$ & $\begin{array}{l}7 I-75 \\
(n=29)\end{array}$ & $\begin{array}{l}76-80 \\
(n=24)\end{array}$ & $\begin{array}{l}\geq 8 \mathrm{I} \\
(\mathrm{n}=22)\end{array}$ \\
\hline & 20 & 0.22 & 0.23 & 0.22 & 0.23 & 0.22 & 0.21 & 0.21 & 0.24 & 0.24 & 0.25 \\
\hline \multirow[t]{4}{*}{ Cadence (steps/min) } & 80 & 118 & 115 & 118 & 118 & 118 & 117 & 120 & 115 & 126 & 127 \\
\hline & 60 & 113 & 112 & 113 & III & 113 & 111 & 116 & 113 & 119 & 114 \\
\hline & 40 & 109 & 107 & 109 & 109 & 111 & 109 & 107 & 107 & 113 & 106 \\
\hline & 20 & 103 & 102 & 101 & 105 & 103 & 105 & 101 & 103 & 103 & 97 \\
\hline \multirow{4}{*}{$\begin{array}{l}\text { Height-adjusted } \\
\text { cadence }\end{array}$} & 80 & 1527 & 1517 & $|53|$ & 1504 & 1533 & 1495 & 1549 & 1500 & 1577 & 1603 \\
\hline & 60 & 1459 & 1464 & 1463 & 1437 & 1453 & $|45|$ & 1485 & 1423 & 1503 & 1432 \\
\hline & 40 & 1400 & 1398 & 1418 & 1412 & 1432 & 1410 & 1399 & $138 \mid$ & 1403 & 1368 \\
\hline & 20 & 1336 & 1336 & 1317 & 1368 & 1344 & 1367 & 1306 & 1330 & $|34|$ & 1257 \\
\hline
\end{tabular}

Abbreviations: Mean (SD), mean (standard deviation); cm/s, centimeter/second; stance time (\%GC), percentage of stance time out of gait cycle; cm, centimeter; s, second; GS, gait speed.

Table 7 Quintile of Gait Parameters for Women of Different Age Groups

\begin{tabular}{|c|c|c|c|c|c|c|c|c|c|c|c|}
\hline \multirow[t]{2}{*}{ Gait Parameters } & \multirow[t]{2}{*}{ Percentile } & \multirow{2}{*}{$\begin{array}{l}\text { Overall } \\
(n=286)\end{array}$} & \multicolumn{9}{|c|}{ Age Group } \\
\hline & & & $\begin{array}{l}21-30 \\
(n=32)\end{array}$ & $\begin{array}{l}3 I-40 \\
(n=34)\end{array}$ & $\begin{array}{l}4 I-50 \\
(n=40)\end{array}$ & $\begin{array}{l}5 I-60 \\
(n=37)\end{array}$ & $\begin{array}{l}61-65 \\
(n=29)\end{array}$ & $\begin{array}{l}66-70 \\
(n=29)\end{array}$ & $\begin{array}{l}7 I-75 \\
(n=29)\end{array}$ & $\begin{array}{l}76-80 \\
(n=28)\end{array}$ & $\begin{array}{l}\geq 81 \\
(n=28)\end{array}$ \\
\hline \multirow[t]{4}{*}{$\mathrm{GS}(\mathrm{cm} / \mathrm{s})$} & 80 & 121.01 & 127.70 & 124.21 & 134.86 & 127.65 & 118.92 & 122.30 & $|14.9|$ & 104.54 & 97.80 \\
\hline & 60 & 112.82 & 120.37 & 117.45 & 119.10 & 117.59 & 112.98 & 110.34 & 107.05 & 93.67 & 94.59 \\
\hline & 40 & 102.60 & 115.22 & 112.92 & 113.44 & 108.09 & $102.5 \mid$ & 105.85 & 97.27 & 83.85 & 85.55 \\
\hline & 20 & 92.01 & $103.4 \mid$ & 98.08 & 102.57 & 100.56 & 97.85 & 94.60 & 87.62 & 76.23 & 69.83 \\
\hline \multirow{4}{*}{$\begin{array}{l}\text { Height-adjusted GS } \\
\left(\mathrm{s}^{-1}\right)\end{array}$} & 80 & 0.77 & 0.79 & 0.78 & 0.87 & 0.82 & 0.76 & 0.79 & 0.72 & 0.70 & 0.68 \\
\hline & 60 & 0.72 & 0.76 & 0.74 & 0.75 & 0.75 & 0.71 & 0.73 & 0.70 & 0.61 & 0.63 \\
\hline & 40 & 0.66 & 0.72 & 0.70 & 0.73 & 0.69 & 0.66 & 0.67 & 0.65 & 0.56 & 0.57 \\
\hline & 20 & 0.60 & 0.64 & 0.63 & 0.64 & 0.64 & 0.63 & 0.64 & 0.57 & 0.50 & 0.47 \\
\hline \multirow[t]{4}{*}{ Step length $(\mathrm{cm})$} & 80 & 60.93 & $65.4 I$ & 62.62 & 63.75 & 63.19 & 61.33 & 58.33 & 58.06 & 54.06 & 51.26 \\
\hline & 60 & 57.55 & 60.89 & 60.39 & 59.30 & 59.06 & 57.79 & 55.03 & 55.04 & 49.98 & 46.84 \\
\hline & 40 & 54.29 & 57.98 & 58.64 & 56.66 & 56.30 & 55.83 & 53.48 & 51.61 & 48.07 & 44.50 \\
\hline & 20 & 50.27 & 55.01 & 55.85 & 54.30 & 53.16 & 52.42 & 51.91 & 46.54 & 40.60 & 41.77 \\
\hline \multirow{4}{*}{$\begin{array}{l}\text { Height-adjusted step } \\
\text { length }\end{array}$} & 80 & 0.39 & 0.40 & 0.39 & 0.40 & 0.40 & 0.39 & 0.38 & 0.37 & 0.36 & 0.35 \\
\hline & 60 & 0.37 & 0.38 & 0.39 & 0.38 & 0.38 & 0.37 & 0.36 & 0.36 & 0.32 & 0.32 \\
\hline & 40 & 0.35 & 0.37 & 0.36 & 0.36 & 0.36 & 0.35 & 0.36 & 0.34 & 0.32 & 0.30 \\
\hline & 20 & 0.33 & 0.34 & 0.36 & 0.34 & 0.34 & 0.34 & 0.34 & 0.31 & 0.28 & 0.28 \\
\hline \multirow[t]{4}{*}{ Step width $(\mathrm{cm})$} & 80 & 62.00 & 66.27 & 63.68 & 64.59 & 64.03 & 62.14 & 58.93 & 58.95 & 55.62 & 52.64 \\
\hline & 60 & 58.57 & 62.35 & 61.11 & 60.52 & 59.92 & 58.92 & 55.93 & 55.77 & 51.18 & 48.86 \\
\hline & 40 & 55.23 & 59.07 & 59.79 & 57.59 & 57.73 & 56.72 & 54.84 & 52.32 & 49.84 & 47.02 \\
\hline & 20 & 51.40 & 55.87 & 56.70 & 55.14 & 53.94 & 53.99 & 52.80 & 48.80 & 42.04 & 43.64 \\
\hline \multirow{4}{*}{$\begin{array}{l}\text { Height-adjusted step } \\
\text { width }\end{array}$} & 80 & 0.40 & 0.41 & 0.40 & 0.41 & 0.41 & 0.40 & 0.38 & 0.38 & 0.37 & 0.36 \\
\hline & 60 & 0.37 & 0.39 & 0.39 & 0.38 & 0.38 & 0.38 & 0.37 & 0.36 & 0.34 & 0.33 \\
\hline & 40 & 0.36 & 0.37 & 0.37 & 0.37 & 0.37 & 0.36 & 0.36 & 0.34 & 0.32 & 0.31 \\
\hline & 20 & 0.33 & 0.35 & 0.36 & 0.35 & 0.34 & 0.35 & 0.34 & 0.32 & 0.29 & 0.29 \\
\hline
\end{tabular}

(Continued) 
Table 7 (Continued).

\begin{tabular}{|c|c|c|c|c|c|c|c|c|c|c|c|}
\hline \multirow[t]{2}{*}{ Gait Parameters } & \multirow[t]{2}{*}{ Percentile } & \multirow{2}{*}{$\begin{array}{l}\text { Overall } \\
(n=286)\end{array}$} & \multicolumn{9}{|c|}{ Age Group } \\
\hline & & & $\begin{array}{l}2 I-30 \\
(n=32)\end{array}$ & $\begin{array}{l}3 I-40 \\
(n=34)\end{array}$ & $\begin{array}{l}4 I-50 \\
(n=40)\end{array}$ & $\begin{array}{l}5 I-60 \\
(n=37)\end{array}$ & $\begin{array}{l}6 I-65 \\
(n=29)\end{array}$ & $\begin{array}{l}66-70 \\
(n=29)\end{array}$ & $\begin{array}{l}7 I-75 \\
(n=29)\end{array}$ & $\begin{array}{l}76-80 \\
(n=28)\end{array}$ & $\begin{array}{l}\geq 81 \\
(n=28)\end{array}$ \\
\hline \multirow[t]{4}{*}{ Stride width $(\mathrm{cm})$} & 80 & 11.60 & 12.09 & 12.29 & 10.16 & 10.86 & 11.24 & 10.47 & 11.32 & 12.82 & 12.88 \\
\hline & 60 & 9.84 & 10.49 & 10.03 & 9.55 & 10.14 & 9.93 & 8.46 & 9.03 & 9.72 & 11.41 \\
\hline & 40 & 8.55 & 8.89 & 9.42 & 8.33 & 8.71 & 9.48 & 7.12 & 8.09 & 8.20 & 9.53 \\
\hline & 20 & 7.09 & 7.60 & 6.74 & 7.03 & 7.44 & 7.01 & 5.49 & 6.71 & 7.15 & 8.29 \\
\hline \multirow{4}{*}{$\begin{array}{l}\text { Feet external rotation } \\
\left({ }^{\circ}\right)\end{array}$} & 80 & 9.54 & 5.71 & 6.07 & 7.56 & 10.30 & 9.72 & 9.36 & 9.60 & 12.23 & 11.70 \\
\hline & 60 & 6.03 & 2.13 & 4.73 & 5.93 & 8.10 & 7.40 & 5.13 & 7.87 & 9.45 & 7.88 \\
\hline & 40 & 3.34 & -1.90 & 3.20 & 2.86 & 4.19 & 4.06 & 1.72 & 5.25 & 4.18 & 6.01 \\
\hline & 20 & 0.28 & -4.10 & 0.80 & -1.08 & 1.02 & 0.33 & 0.23 & 2.37 & 1.21 & 2.78 \\
\hline \multirow[t]{4}{*}{ Stance time (\%GC) } & 80 & 63.02 & 62.28 & 62.12 & 62.90 & 62.69 & 62.75 & 63.00 & 62.96 & 64.83 & 63.83 \\
\hline & 60 & 62.16 & 61.10 & 61.45 & 61.68 & 61.84 & 62.20 & 62.45 & 61.88 & 63.71 & 63.13 \\
\hline & 40 & 61.11 & 60.38 & 60.61 & 60.57 & 61.03 & 61.55 & 61.15 & 61.04 & 62.78 & 62.46 \\
\hline & 20 & 60.32 & 59.81 & 59.65 & 59.95 & 60.42 & 60.61 & 60.47 & 60.32 & 61.42 & 61.27 \\
\hline \multirow[t]{4}{*}{ Single support time (s) } & 80 & 0.42 & 0.43 & 0.43 & $0.4 I$ & 0.41 & 0.43 & 0.42 & 0.43 & 0.43 & 0.43 \\
\hline & 60 & 0.40 & 0.42 & 0.41 & 0.40 & 0.40 & $0.4 \mathrm{I}$ & 0.40 & 0.41 & 0.40 & $0.4 I$ \\
\hline & 40 & 0.39 & 0.40 & 0.40 & 0.38 & 0.39 & 0.40 & 0.38 & 0.40 & 0.39 & 0.39 \\
\hline & 20 & 0.38 & 0.39 & 0.39 & 0.37 & 0.38 & 0.38 & 0.37 & 0.37 & 0.37 & 0.36 \\
\hline \multirow[t]{4}{*}{ Double support time (s) } & 80 & 0.29 & 0.26 & 0.26 & 0.29 & 0.27 & 0.29 & 0.29 & 0.28 & 0.37 & 0.33 \\
\hline & 60 & 0.25 & 0.24 & 0.24 & 0.23 & 0.24 & 0.25 & 0.25 & 0.25 & 0.30 & 0.28 \\
\hline & 40 & 0.23 & 0.21 & 0.22 & 0.21 & 0.22 & 0.23 & 0.22 & 0.22 & 0.26 & 0.25 \\
\hline & 20 & 0.20 & 0.19 & 0.19 & 0.18 & 0.21 & 0.22 & 0.20 & 0.21 & 0.22 & 0.24 \\
\hline \multirow[t]{4}{*}{ Cadence (steps/min) } & 80 & 123 & 123 & 120 & 129 & 123 & 122 & 126 & 122 & $12 \mid$ & 124 \\
\hline & 60 & 118 & 118 & 118 & 123 & 117 & 118 & 122 & 117 & 115 & 115 \\
\hline & 40 & 114 & 113 & 113 & 116 & 115 & 114 & 117 & 113 & 110 & 112 \\
\hline & 20 & 107 & 107 & 108 & 109 & 110 & 104 & 106 & 107 & 102 & 100 \\
\hline \multirow{4}{*}{$\begin{array}{l}\text { Height-adjusted } \\
\text { cadence }\end{array}$} & 80 & 1538 & 1566 & 1528 & 1611 & 1564 & 1528 & 1552 & 1517 & 1493 & 1489 \\
\hline & 60 & 1471 & 1483 & 1474 & 1531 & $147 \mid$ & $|48|$ & 1504 & 1448 & 1400 & 1405 \\
\hline & 40 & 1417 & 1429 & 1434 & $|47|$ & 1437 & 1404 & 1449 & $|38|$ & 1339 & $|36|$ \\
\hline & 20 & 1342 & $|36|$ & 1346 & 1406 & 1387 & 1296 & $|32|$ & 1346 & 1253 & 1220 \\
\hline
\end{tabular}

Abbreviations: Mean (SD), mean (standard deviation); cm/s, centimeter/second; stance time (\%GC), percentage of stance time out of gait cycle; cm, centimeter; s, second; GS, gait speed.

$0.02 \mathrm{~s}$ longer in double support. ${ }^{10,14}$ Additionally, men walked with a wider stride width ${ }^{14,41,42}$ possibly due to the valgus knee angle ${ }^{41}$ and weaker hip abductor strength in women. ${ }^{42}$ Men also concurrently externally rotated their feet more during walking. The greater lower extremity external rotation and wider stride width could yield better stability in the frontal plane during walking, potentially reducing the risk of falling in men. Future studies are required to examine the clinical implications and the modifiable factors associated with feet external rotation and stride width, to better guide practitioners in prescribing customized preventive programs, especially for middleaged adults.

\section{Strengths and Limitations}

The strengths of this study are its population-based nature and thoroughness of data collection. It also has a few limitations. As a cross-sectional study, causality between risk factors and gait cannot be inferred, and age-related changes may not truly represent the longitudinal trajectories experienced by South East Asian adults. Our findings could potentially be confounded by the underlying comorbidities (as reported in Table 1) of the older adults. However, the prevalence of diabetes, hypertension and hypercholesterolemia was between $9 \%$ and $34 \%$ of the Singapore population. The exclusion of the adults with these comorbidities would pose a significant challenge to 
recruit older adults, especially those beyond the eighth decade and may not well represent the Singapore adult and older population of interest. A longitudinal study is suggested to further examine the compound effect of chronicity of hypertension, hypercholesterolemia and diabetes on spatiotemporal gait parameters, especially for men. Additionally, our findings on the multi-ethnic South East Asian population may not generalize to a different population mix. We did not set out to study the ethnic differences in this normative study of gait parameters as non-Chinese races made up only $18 \%$ in our population. Future studies may explore the ethnic differences in gait.

\section{Conclusion}

Our study contributes insights to the understanding of the effects of aging on gait speed and spatiotemporal gait parameters. Differences between men and women are not systematically present across all gait parameters. Importantly, when adjusted for height, women had faster gait than men, possibly confounded by the underlying comorbidities of hypertension, hypercholesterolemia and diabetes. Compared to women, men walked with greater feet external rotation and wider stride width. We report the lowest quintile for gait speed of $0.9 \mathrm{~m} / \mathrm{s}$ for both sexes, which is below the recommended cut-off of $1.0 \mathrm{~m} / \mathrm{s}$ for Asian populations. Longitudinal studies are required to better elucidate the trajectories and predictors of changes in gait speed with age.

\section{Acknowledgment}

The authors gratefully acknowledged the strong support of Professor Pang Weng Sun in making this Yishun Study possible, and the support given by Sylvia Ngu, Aizuriah bin Mohamed Ali, Dr Lilian Chye, Mary Ng Pei Ern, Chua Xing Ying and Shermaine Thein in this study.

\section{Funding}

This project was supported as part of a core funding from the Ministry of Health, Singapore.

\section{Disclosure}

The authors have no conflicts of interest to declare for this work.

\section{References}

1. Asian Working Group for Sarcopenia. 2019 consensus update on sarcopenia diagnosis and treatment. J Am Med Dir Assoc. 2020;21 (3):300-307. doi:10.1016/j.jamda.2019.12.012
2. Montero-Odasso MM, Barnes B, Speechley M, et al. Disentangling cognitive-frailty: results from the gait and brain study. J Gerontol A Biol Sci Med Sci. 2016;71(11):1476-1482. doi:10.1093/gerona/glw044

3. Rodríguez-Sanz D, Tovaruela-Carrión N, López-López D, et al. Foot disorders in the elderly: a mini-review. Dis Mon. 2018;64(3):64-91. doi:10.1016/j.disamonth.2017.08.001

4. Brognara L, Navarro-Flores E, Iachemet L, Serra-Catalá N, Cauli O. Beneficial effect of foot plantar stimulation in gait parameters in individuals with Parkinson's disease. Brain Sci. 2020;10(2):69.

5. Studenski S, Perera S, Patel K, et al. Gait speed and survival in older adults. JAMA Netw Open. 2011;305(1):50-58.

6. Zeng P, Han Y, Pang J, et al. Sarcopenia-related features and factors associated with lower muscle strength and physical performance in older Chinese: a cross sectional study. BMC Geriatr. 2016;16(1):45.

7. Hall KS, Cohen HJ, Pieper CF, et al. Physical performance across the adult life span: correlates with age and physical activity. J Gerontol A Biol Sci Med Sci. 2017;72(4):572-578. doi:10.1093/gerona/glw120

8. Yoshimura N, Oka H, Muraki S, et al. Reference values for hand grip strength, muscle mass, walking time, and one-leg standing time as indices for locomotive syndrome and associated disability: the second survey of the ROAD study. J Orthop Sci. 2011;16(6):768-777. doi:10.1007/s00776-011-0160-1

9. Seino S, Shinkai S, Fujiwara Y, et al. Reference values and age and sex differences in physical performance measures for community-dwelling older Japanese: a pooled analysis of six cohort studies. PLoS One. 2014;9(6):e99487. doi:10.1371/journal.pone.009 9487

10. Kawai H, Taniguchi Y, Seino S, et al. Reference values of gait parameters measured with a plantar pressure platform in community-dwelling older Japanese adults. Clin Interv Aging. 2019;14:1265. doi:10.2147/CIA.S213216

11. Rosano C, Aizenstein HJ, Studenski S, Newman AB. A regions-ofinterest volumetric analysis of mobility limitations in community-dwelling older adults. J Gerontol A Biol Sci Med Sci. 2007;62(9):1048-1055. doi:10.1093/gerona/62.9.1048

12. Raz N, Gunning-Dixon F, Head D, Rodrigue KM, Williamson A, Acker JD. Aging, sexual dimorphism, and hemispheric asymmetry of the cerebral cortex: replicability of regional differences in volume. Neurobiol Aging. 2004;25(3):377-396. doi:10.1016/S0197-4580(03) 00118-0

13. Frimenko R, Goodyear C, Bruening D. Interactions of sex and aging on spatiotemporal metrics in non-pathological gait: a descriptive meta-analysis. Physiotherapy. 2015;101(3):266-272. doi:10.1016/j. physio.2015.01.003

14. Hollman JH, McDade EM, Petersen RC. Normative spatiotemporal gait parameters in older adults. Gait Posture. 2011;34(1):111-118. doi:10.1016/j.gaitpost.2011.03.024

15. Sofuwa O, Nieuwboer A, Desloovere K, Willems AM, Chavret F, Jonkers I. Quantitative gait analysis in Parkinson's disease: comparison with a healthy control group. Arch Phys Med Rehabil. 2005;86 (5):1007-1013. doi:10.1016/j.apmr.2004.08.012

16. Taniguchi Y, Yoshida H, Fujiwara Y, Motohashi Y, Shinkai S. A prospective study of gait performance and subsequent cognitive decline in a general population of older Japanese. J Gerontol A Biol Sci Med Sci. 2012;67(7):796-803. doi:10.1093/gerona/glr243

17. El Haber N, Erbas B, Hill KD, Wark JD. Relationship between age and measures of balance, strength and gait: linear and non-linear analyses. Clin Sci (Lond). 2008;114(12):719-727. doi:10.1042/ CS20070301

18. Chui KK, Lusardi MM. Spatial and temporal parameters of selfselected and fast walking speeds in healthy community-living adults aged 72-98 years. J Geriatr Phys Ther. 2010;33(4):173-183. doi:10.1519/JPT.0b013e3181ff262c

19. Singapore Department of Statistics (DOS) [Home page on the Internet]. Base. 2020. Available from: https://www.singstat.gov.sg. Accessed June 27, 2020. 
20. Hogg RV, Tanis EA, Zimmerman DL. Probability and Statistical Inference. England: Pearson; 2015.

21. Callisaya ML, Blizzard L, Schmidt MD, McGinley JL, Srikanth VK. Sex modifies the relationship between age and gait: a population-based study of older adults. J Gerontol A Biol Sci Med Sci. 2008;63(2):165-170. doi:10.1093/gerona/63.2.165

22. Holtzer R, Wang C, Lipton R, Verghese J. The protective effects of executive functions and episodic memory on gait speed decline in aging defined in the context of cognitive reserve. $J$ Am Geriatr Soc. 2012;60(11):2093-2098. doi:10.1111/j.1532-5415.2012.04193.x

23. Beauchet O, Allali G, Sekhon H, et al. Guidelines for assessment of gait and reference values for spatiotemporal gait parameters in older adults: the Biomathics and Canadian Gait Consortiums initiative. Front Hum Neurosci. 2017;11:353. doi:10.3389/fnhum.2017.00353

24. Brach JS, Perera S, Studenski S, Newman AB. The reliability and validity of measures of gait variability in community-dwelling older adults. Arch Phys Med Rehabil. 2008;89(12):2206-2293. doi:10.10 16/j.apmr.2008.06.010

25. Priest AW, Salamon KB, Hollman JH. Age-related differences in dual task walking: a cross sectional study. J Neuroeng Rehabil. 2008;5 (1):29. doi:10.1186/1743-0003-5-29

26. Yamaguchi T, Masani K. Effects of age-related changes in step length and step width on the required coefficient of friction during straight walking. Gait Posture. 2019;69:195-201. doi:10.1016/j.gaitpost.2019. 02.005

27. GAITRite. Electronic Walkway Technical Reference. Available from: https://www.procarebv.nl/wp-content/uploads/2017/01/Technischeaspecten-GAITrite-Walkway-System.pdf. Accessed August 4, 2020.

28. Morio Y, Izawa KP, Omori Y, et al. The relationship between walking speed and step length in older aged patients. Diseases. 2019;7(1):17. doi:10.3390/diseases 7010017

29. Eppeland SG, Myklebust G, Hodt-Billington C, Moe-Nilssen R. Gait patterns in subjects with rheumatoid arthritis cannot be explained by reduced speed alone. Gait Posture. 2009;29(3):499-503. doi:10.10 16/j.gaitpost.2008.11.010

30. Maki BE, McIlroy WE. Change-in-support balance reactions in older persons: an emerging research area of clinical importance. Neurol Clin. 2005;23(3):751-783. doi:10.1016/j.ncl.2005.01.002

31. Juul A, Skakkebaek NE. Androgens and the ageing male. Hum Reprod Update. 2002;8(5):423-433. doi:10.1093/humupd/8.5.423
32. Velez MP, Alvarado BE, Rosendaal N, et al. Age at natural menopause and physical functioning in postmenopausal women: the Canadian Longitudinal Study on Aging. Menopause. 2019;26 (9):958. doi:10.1097/GME.0000000000001362

33. Kiyoshige Y, Watanabe E. Fatty degeneration of gluteus minimus muscle as a predictor of falls. Arch Gerontol Geriatr. 2015;60 (1):59-61. doi:10.1016/j.archger.2014.07.013

34. Andrews AW, Thomas MW, Bohannon RW. Normative values for isometric muscle force measurements obtained with hand-held dynamometers. Phys Ther. 1996;76(3):248-259. doi:10.1093/ptj/ 76.3.248

35. Kubinski SN, McQueen CA, Sittloh KA, Dean JC. Walking with wider steps increases stance phase gluteus medius activity. Gait Posture. 2015;41(1):130-135. doi:10.1016/j.gaitpost.2014.09.013

36. Shimada H, Makizako H, Doi T, Tsutsumimoto K, Suzuki T. Incidence of disability in frail older persons with or without slow walking speed. $J$ Am Med Dir Assoc. 2015;16(8):690-696. doi:10.1016/j.jamda.2015.03.019

37. Kim M, Won CW. Sarcopenia is associated with cognitive impairment mainly due to slow gait speed: results from the Korean Frailty and Aging Cohort Study (KFACS). Int J Environ Res Public Health. 2019;16(9):1491. doi:10.3390/ijerph16091491

38. Lyle AN, Raaz U. Killing me unsoftly: causes and mechanisms of arterial stiffness. Arterioscler Thromb Vasc Biol. 2017;37(2):e1. doi:10.1161/ATVBAHA.116.308563

39. Liu W. Relationship between blood lipid and arterial stiffness in hypertension. Clin Exp Med. 2019;42(3):E47-55.

40. Gonzales JU. Gait performance in relation to aortic pulse wave velocity, carotid artery elasticity and peripheral perfusion in healthy older adults. Clin Physiol Funct Imaging. 2013;33(4):245-251. doi:10.1111/cpf.12019

41. Cho SH, Park JM, Kwon OY. Gender differences in three dimensional gait analysis data from 98 healthy Korean adults. Clin Biomech. 2004;19(2):145-152.

42. Ko S-U, Tolea MI, Hausdorff JM, Ferrucci L. Sex-specific differences in gait patterns of healthy older adults: results from the Baltimore longitudinal study of aging. J Biomech. 2011;44 (10):1974-1979. doi:10.1016/j.jbiomech.2011.05.005
Clinical Interventions in Aging

\section{Publish your work in this journal}

Clinical Interventions in Aging is an international, peer-reviewed journal focusing on evidence-based reports on the value or lack thereof of treatments intended to prevent or delay the onset of maladaptive correlates of aging in human beings. This journal is indexed on PubMed Central, MedLine, CAS, Scopus and the Elsevier
Bibliographic databases. The manuscript management system is completely online and includes a very quick and fair peer-review system, which is all easy to use. Visit http://www.dovepress.com/ testimonials.php to read real quotes from published authors. 